Article

\title{
Extracellular Nucleotides Selectively Induce Migration of Chondrocytes and Expression of Type II Collagen
}

\author{
Marcin Szustak and Edyta Gendaszewska-Darmach * (1D \\ Institute of Molecular and Industrial Biotechnology, Faculty of Biotechnology and Food Sciences, Lodz \\ University of Technology, Stefanowskiego 4/10, 90-924 Lodz, Poland; marcin.szustak@p.lodz.pl \\ * Correspondence: edyta.gendaszewska-darmach@p.lodz.pl; Tel.: +48-426313443
}

Received: 25 June 2020; Accepted: 22 July 2020; Published: 23 July 2020

\begin{abstract}
The migration of chondrocytes from healthy to injured tissues is one of the most important challenges during cartilage repair. Additionally, maintenance of the chondrogenic phenotype remains another limitation, especially during monolayer culture in vitro. Using both the differentiated and undifferentiated chondrogenic ATDC5 cell line, we showed that extracellular nucleotides are able to increase the migration rate of chondrocytes without affecting their chondrogenic phenotype. We checked the potency of natural nucleotides (ATP, ADP, UTP, and UDP) as well as their stable phosphorothioate analogs, containing a sulfur atom in the place of one nonbridging oxygen atom in a phosphate group. We also detected P2y1, P2y2, P2y4, P2y6, P2y12, P2y13, and P2y14 mRNA transcripts for nucleotide receptors, demonstrating that $P 2 y 1$ and $P 2 y 13$ are highly upregulated in differentiated ATDC5 cells. We showed that ADP $\beta S$, UDP $\beta S$, and ADP are the best stimulators of migration of differentiated chondrocytes. Additionally, ADP and ADP $\beta$ S positively affected the expression of type II collagen, a structural component of the cartilage matrix.
\end{abstract}

Keywords: P2Y receptors; chondrocytes; migration; differentiation

\section{Introduction}

The cartilage is extremely susceptible to damage due to its load-bearing capability. If left untreated after injury, cartilage eventually degenerates, causing chronic osteoarthritis. The problem of cartilage repair is a growing civilization problem since self-regeneration of cartilage tissue is usually very limited. This is mainly due to the lack of blood vessels in this space, which are necessary to initiate the repair process. The problem is also the negligible amount of chondrogenic and progenitor cells surrounding the tissue area that migrate from the healthy tissue. The improved migration ability of chondrocytes is therefore considered to be essential for new therapeutic strategies, especially as in physiological settings, the dense pericellular matrix surrounding the chondrocytes makes migration a challenging process [1].

A number of studies have shown that different stimuli accelerate the rate of chondrocyte movement. For example, chondrocytes were demonstrated to be migrating in response to peripheral mononuclear blood-derived cells [2], insulin-like growth factor-1 [3], hyaluronic acid and basic fibroblast growth factor [4], sulfated hyaluronic acid [5], fibrin [6], or WNT5A protein [7]. We showed previously that extracellular nucleotides induce migration of HaCaT keratinocytes and HeLa cells via activation of P2Y nucleotide receptors [8,9]. Eight subtypes of P2Y family, namely P2Y1, P2Y2, P2Y4, P2Y6, P2Y11, P2Y12, P2Y13, and P2Y14, belong to the G protein-coupled receptors (GPCRs) family and regulate a variety of cellular processes, including proliferation, differentiation, secretion, cell adhesion, and migration. P2Y1, P2Y12, and P2Y13 are activated preferably by ADP while P2Y6 is activated by UDP. P2Y11 prefers ATP 
as an agonist while P2Y2 reacts to both ATP and UTP. UTP is also the P2Y4 agonist. Nucleotide sugar conjugate (UDP-glucose) activates the P2Y14 receptor [10]. However, there are scarce reports of the role of extracellular nucleotides on chondrogenic biology. Since some subtypes of P2Y receptors have been demonstrated to be expressed in chondrocytes [11], we hypothesized that purine and pyrimidine nucleotides may play relevant roles in the migration of chondrocytes. Expanding our understanding of purinergic signaling in the biology of chondrocytes could be translated in the future into clinical benefits. Unfortunately, extracellular nucleotides are hydrolyzed by specific ectonucleotidases present in both the cartilage matrix and synovial fluid [12]. Hence, hereby, we tested the ability to stimulate chondrocyte migration not only by unmodified nucleotides but also by their phosphorothioate analogs since our previous studies showed that replacing an oxygen atom with a sulfur in a phosphate group conferred significant resistance to enzymatic hydrolysis $[9,13]$. Stable analogs of nucleotides (e.g., ADP $\beta S$ or UDP $\beta S$ ) are commonly utilized in studies addressing purinergic signaling $[14,15]$.

Besides a low migratory ability, another limitation of adult chondrocytes is the phenomenon of dedifferentiation during their extensive expansion in vitro, the step required for autologous chondrocyte implantation (ACI) being the first-line cell therapy for critical cartilage defects [16]. Dedifferentiation of chondrocytes is accompanied with the gradual loss of cartilage-specific molecular markers, such as collagen type II (COL2A1), aggrecan, or SRY (sex-determining region Y)-box 9 (SOX9) transcription factor, whilst at the same time, the cells acquire a fibroblast-like phenotype, characterized by the expression of collagen type I (COL1A). Eventually, chondrocytes undergo final differentiation and become hypertrophic ones characterized by type $X$ collagen and matrix metalloproteinase- 13 expression. RUNX2 (Runt-related transcription factor 2) is responsible for hypertrophic differentiation and is directly inhibited by SOX9, a master transcription factor that regulates chondrocyte differentiation. Phenotypic conversion to hypertrophic chondrocytes is observed in the degenerative articular cartilage of osteoarthritis. Besides RUNX2, many genes are directly targeted by SOX9, including the gene encoding COL2A1 [17-19]. Therefore, we also evaluated if supplementation of the culture medium with extracellular nucleotides affects the expression of cartilage marker molecules.

As the first step of our studies, we analyzed the expression pattern of P2Y receptors in differentiated and undifferentiated chondrogenic ATDC 5 cells. Subsequently, using both the differentiated and undifferentiated ATDC5 cell line, we compared the potential of various P2Y natural agonists and their stable analogs as agents affecting the migration and differentiation of chondrocytes.

\section{Results}

\subsection{The Chondrogenic Phenotype of ATDC5 Growing under Differentiating Conditions}

The murine ATDC5 cell line is a well-recognized model for in vitro chondrogenesis studies. It retains the properties of chondroprogenitor cells and exhibits almost the same characteristics of chondrogenesis as mesenchymal stem cells [20,21]. Differentiation of ATDC 5 cells can be induced by the presence of chondrogenic medium; however, literature reports define various compositions of such media. We chose differentiating medium consisting of DMEM/F12 (1:1), $2 \mathrm{mM}$ glutamine, antibiotics (100 U/mL penicillin, $100 \mathrm{mg} / \mathrm{mL}$ neomycin, $2.5 \mu \mathrm{g} / \mathrm{mL}$ amphotericin B), insulin-transferrin-sodium selenite solution (ITS, $10 \mu \mathrm{g} / \mathrm{mL}$ insulin, $5.5 \mu \mathrm{g} / \mathrm{mL}$ transferrin, $67 \mathrm{ng} / \mathrm{mL}$ sodium selenite), $50 \mu \mathrm{g} / \mathrm{mL}$ L-ascorbic acid, $100 \mathrm{nM}$ dexamethasone, and $10 \mathrm{ng} / \mathrm{mL}$ TGF- $\beta 2$ [22] and confirmed its utility during the first stage of the study. Cells were grown in differentiation medium for 14 days because this period was described as necessary for sufficient differentiation [23]. As an undifferentiated control, we incubated ATDC5 cells in standard growth medium (DMEM/F12 (1:1), 2 mM glutamine, antibiotics, 5\% fetal bovine serum). Then, we compared the morphological changes and expression of chondrogenic markers after the 14-day culture of ATDC5 in standard and differentiation medium. Cells growing in the monolayer culture in standard growth medium exhibited a fibroblast-like morphology (Figure 1A). 

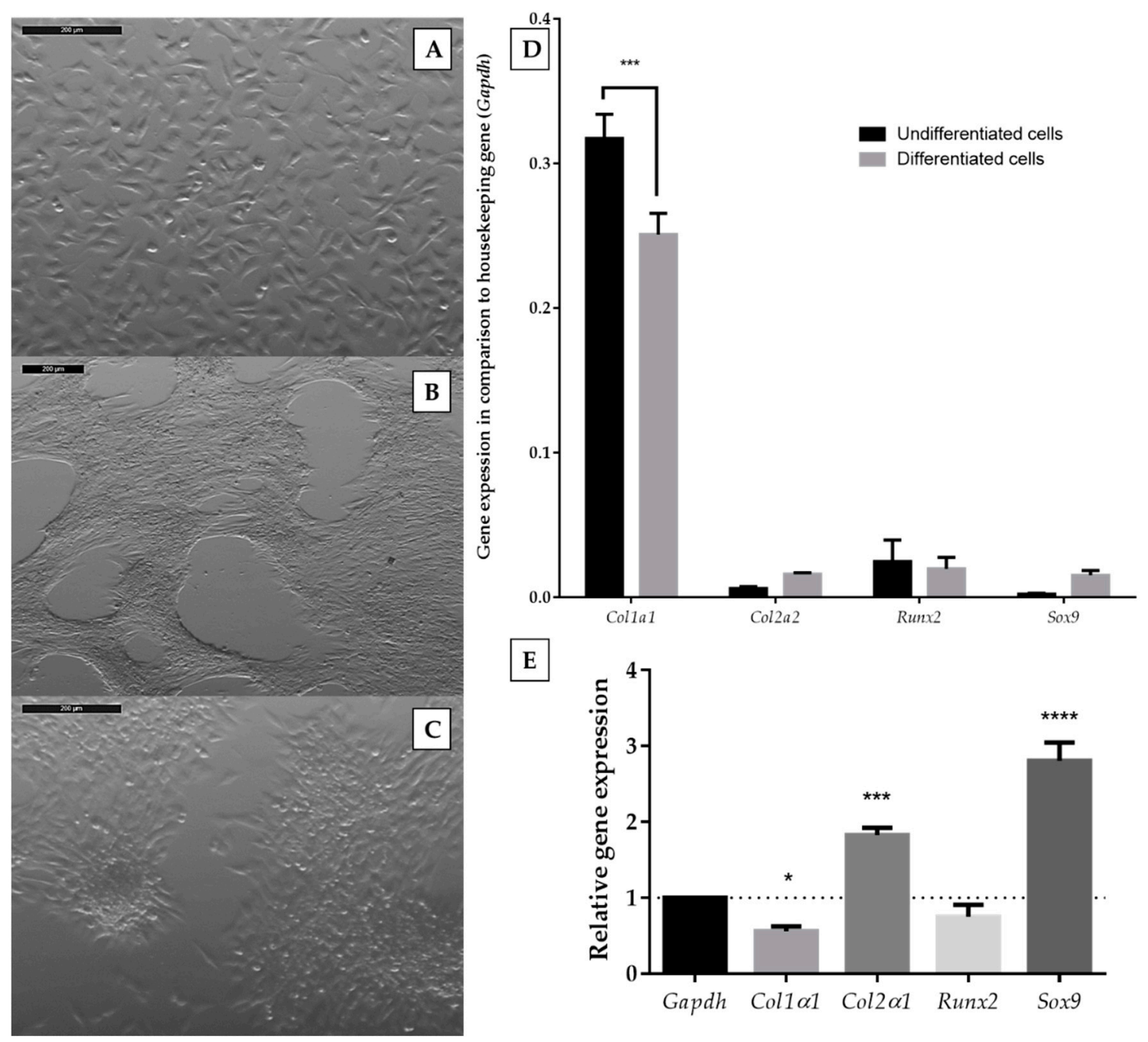

Figure 1. Morphology of ATDC5 cells grown for 14 days in standard growth medium (A) or in differentiation medium $(\mathbf{B}, \mathbf{C})$. The images were captured with a Leica 205C microscope and processed with the Leica Application Suite. The scale bar represents the length of $200 \mu \mathrm{m}$; expression levels of chondrocyte-specific genes in undifferentiated and differentiated ATDC5 cells in comparison to a Gapdh housekeeping gene (D), and relative gene expression calculated with Livak's method [24] (E). Data represent the means \pm standard error of the mean (SEM) from at least three independent experiments. Changes of genes expression between undifferentiated and differentiated cells for different genes were analyzed with two-way ANOVA with Tukey's comparison test (D). Statistical difference between the control of a Gapdh housekeeping gene and tested genes were analyzed with one-way ANOVA (E). $p<0.05\left(^{*}\right), p<0.001\left(^{* * *}\right)$, and $p<0.0001\left(^{* * * *}\right)$ for gene expression significantly different from undifferentiated control cells.

On the contrary, ATDC5 cells present in differentiating medium tended to group (Figure 1B) and form characteristic rounded clumps (Figure 1C). We also utilized reverse transcription quantitative polymerase chain reaction (RT-qPCR) for the quantification of type 1 collagen (Col1 $\alpha 1$ ), type 2 collagen (Col2 1 1), SRY-Box 9 (Sox9), and runt-related transcription factor 2 (Runx2) mRNA expression. The expression of Col1a1 was downregulated in ATDC5 cells growing in a differentiating medium, while Col2a1 and Sox 9 were upregulated (Figure 1D,E). The expression of Runx2 did not change. Therefore, the chosen differentiating medium was used for further experiments. 


\subsection{Expression of P2Y Receptors in Differentiated and Undifferentiated ATDC5 Cells}

In the present study, we examined the expression of all P2Y receptors in ATDC5 cells using quantitative RT-PCR. P2Y11 expression was not studied due to the lack of a P2y11 gene ortholog in the mouse genome [25]. Since the differentiation process may affect the expression level of P2Y receptors, at the beginning, we determined the expression pattern of $\mathrm{P} 2 \mathrm{Y}$ receptors in undifferentiated and differentiated cells. In undifferentiated ATDC5 cells, P2y4, P2y6, and P2y14 mRNA transcripts showed the highest expression of all receptors studied (Figure 2A).
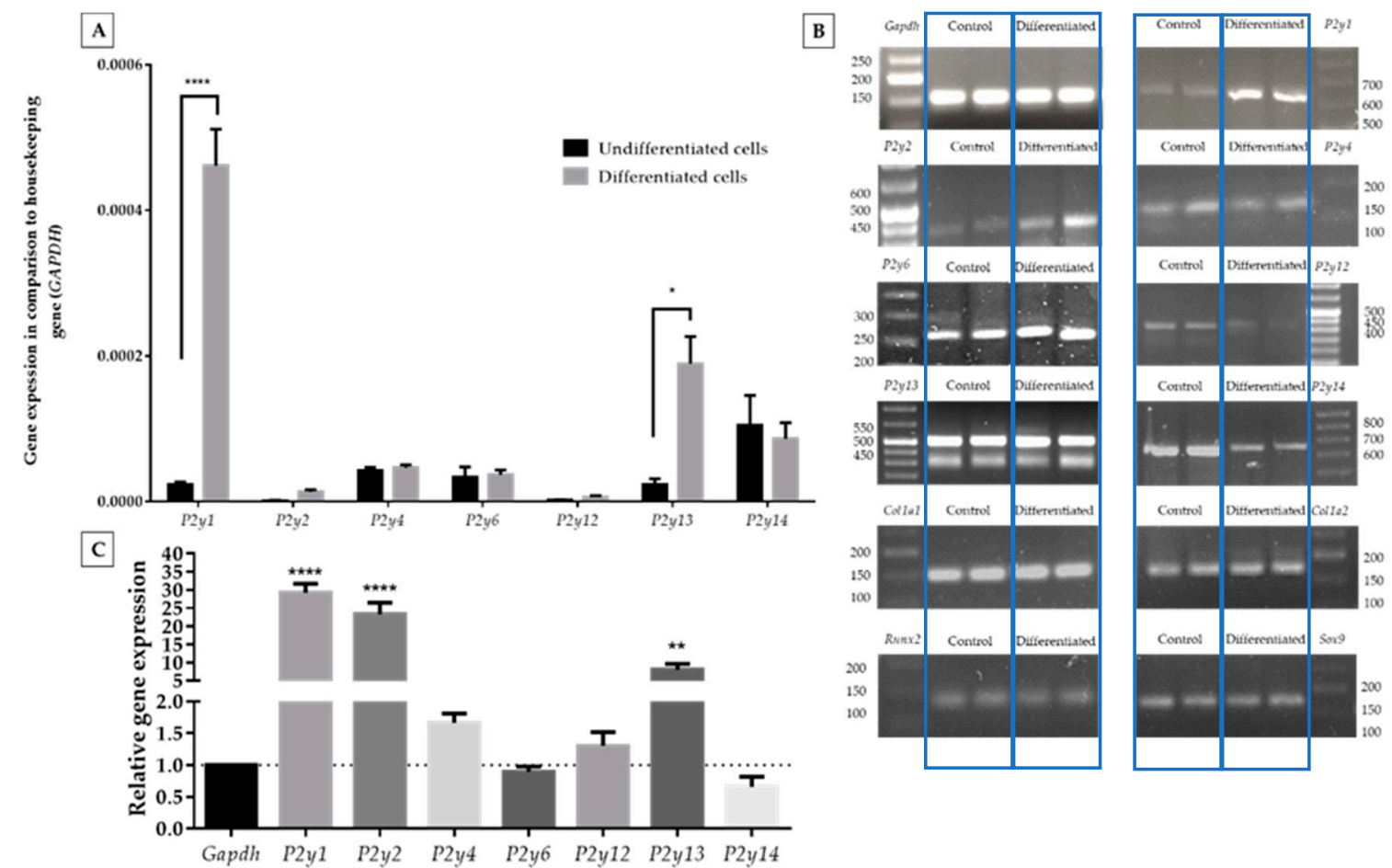

Figure 2. Comparison of P2Y receptor gene expression levels between ATDC5 cells grown in standard growth medium or in differentiation medium in comparison to a Gapdh housekeeping gene (A). Significant differences were calculated with two-way ANOVA with Tukey post-hoc test. The relative gene expression calculated with Livak's method [24] showed changes in the expression level while Gapgh was constant (C). An image of DNA qPCR products separated on a 3\% agarose gel (two repeated samples in each case) along with a DNA ladder and documented with the ChemiDoc Imaging system (B). qPCR products were separated with 3\% agarose gel electrophoresis and documented with the ChemiDoc Imaging system (B). Statistical differences vs. control were calculated with one-way ANOVA. Data represent the means \pm SEM from at least three independent experiments. $p<0.05\left(^{*}\right), p<0.01\left(^{* *}\right)$, and $\left.p<0.0001{ }^{* * * *}\right)$ for gene expression significantly different from undifferentiated control cells.

The differentiation process highly upregulated the expression of $P 2 y 1, P 2 y 2$, and $P 2 y 13$ genes. The expression levels of all remaining receptors were upregulated (Figure 2A,C). The biggest increase was observed for the P2y1 gene (ca. 30-fold) and $P 2 y 2$ gene (ca. 20-fold). However, the relatively high growth of $P 2 y 2$ was connected with its very low expression before the differentiation process. P2y13 presented a ca.8-fold increase, which is confirmed by relative gene expression calculations. All qPCR products showed a desirable agarose gel pattern (Figure 2B).

\subsection{Migration of ATDC5 Cells in the Presence of Extracellular Nucleotides}

We targeted the evaluation of extracellular nucleotides as potentially promising stimulators of chondrocyte migration. We chose nucleoside $5^{\prime}$-diphosphates (ADP, UDP), nucleoside $5^{\prime}$-triphosphates (ATP, UTP), and nucleoside 5'-mono (TMPS, UMPS, AMPS), di (ADP $\beta S, U D P \beta S)$, or triphosphorothioate 
analogs (ATP $\gamma \mathrm{S}, \mathrm{UTP} \gamma \mathrm{S}$ ) for the studies. In the migration studies, we utilized serum-free starving medium instead of standard growth medium to suppress cell proliferation and deplete serum factors that could influence cell migration. We utilized a wound scratch assay, where a linear scratch was across the surface of a confluent plate dish. Then, confluent cells were stimulated with nucleotides for $48 \mathrm{~h}$. Cells growing in starving medium were positively induced to migrate by natural nucleotides like UDP and UTP. Moreover, TMPS and UMPS also increased this process but to a lesser extent. We also observed an inhibitory effect in the case of AMPS, ATP $\gamma$ S, and UTP $\gamma$ S. All other tested compounds did not show any significant differences (Figure $3 \mathrm{~A}$ ). When differentiated cells were used, we noticed a dramatic change in the results (Figure 3B). In this case, only ATP diminished migration. ADP, UMPS, $\mathrm{UTP} \gamma \mathrm{S}, \mathrm{UDP} \beta \mathrm{S}$, and ADP $\beta S$ significantly accelerated cell migration. The most prominent activity was observed for ADP $\beta S$, UDP $\beta$, and ADP.
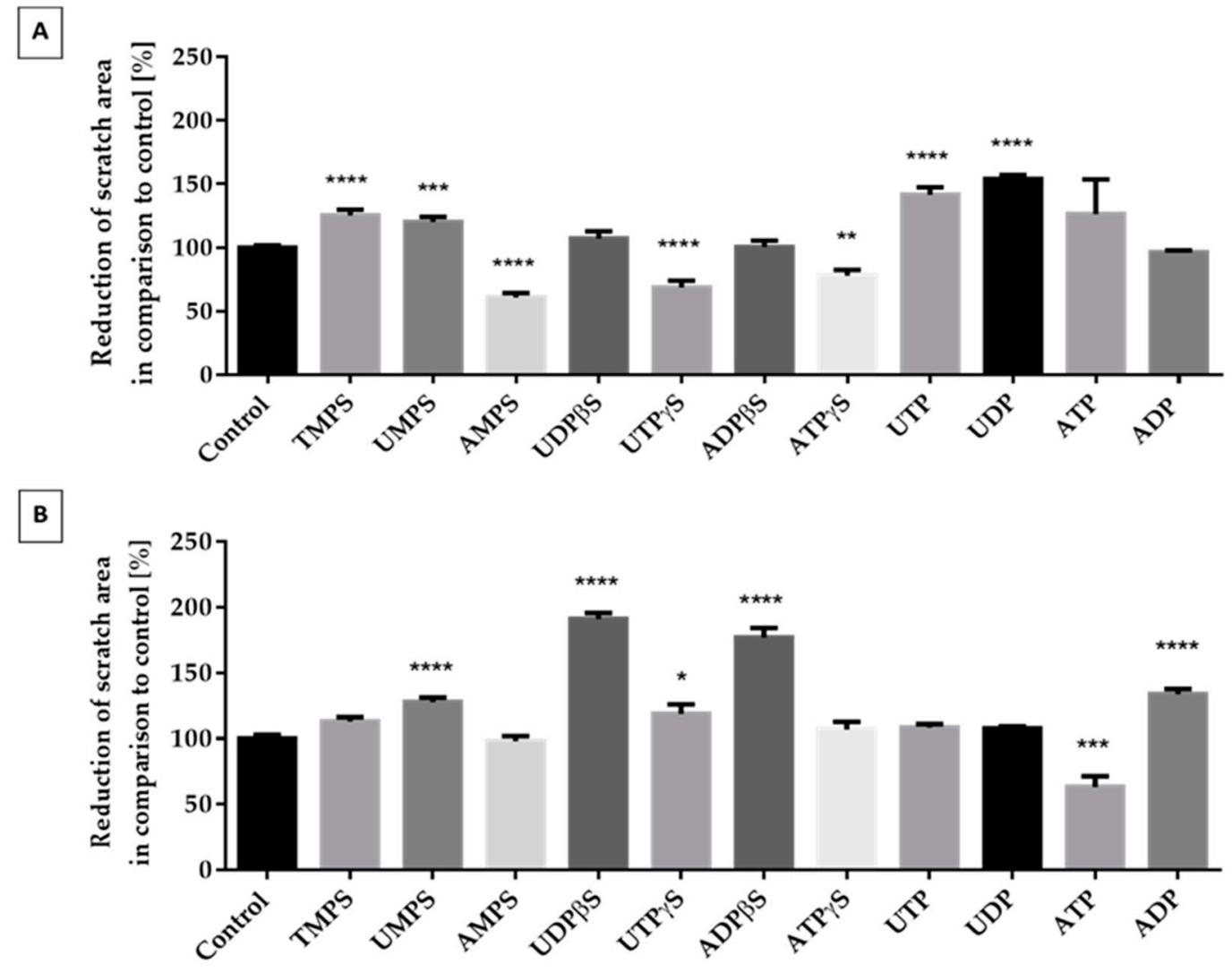

Figure 3. The effect of unmodified nucleotides and their phosphorothioate analogs on the migration of ATDC5 cells grown for $48 \mathrm{~h}$ in starving medium (A) or in differentiation medium (B). The extent of migration was documented with the Leica 205C microscope and processed in Leica Application Suite. Results represent a percentage of wound reduction in comparison to unstimulated control cells. Data represent the means \pm SEM from at least six independent experiments. $p<0.01\left(^{* *}\right), p<0.001\left(^{* * *}\right)$, and $\left.p<0.0001{ }^{* * * *}\right)$ for reduction of scratch area significantly different from untreated control cells.

2.4. The Influence of Extracellular Nucleotides on the Expression of Cartilage-Related Gene Markers in Differentiated and Undifferentiated ATDC5 Cells

Compounds that enhance the migration of chondrocytes cannot negatively affect the differentiation process. Hence, we analyzed the expression level of characteristic differentiation marker genes (Col1a1, Col2a1, Sox9, and Runx2) stimulated with selected nucleotides. We decided to test compounds with favorable (ADP, UDP $\beta$ S, and ADP $\beta S$ ), neutral (UTP, TMPS), and negative (ATP) promigratory properties, taking into consideration differentiated ATDC5 cells. Among the nucleotides applied to undifferentiated cells, only ATP reduced the expression of all genes studied and the most significant downregulation was observed for Col2a1. More important results were obtained with nucleotides added 
to differentiated cells. Tested compounds did not significantly influence the expression level of the Runx 2 and Sox9 genes. TMPS, ATP, and UTP significantly downregulated the Col1 $\alpha 1$ expression level. Interestingly, ADP and ADP $\beta S$ strongly enhanced the expression characteristic for the differentiated cell gene Col2 $\alpha 1$ (Figure 4).

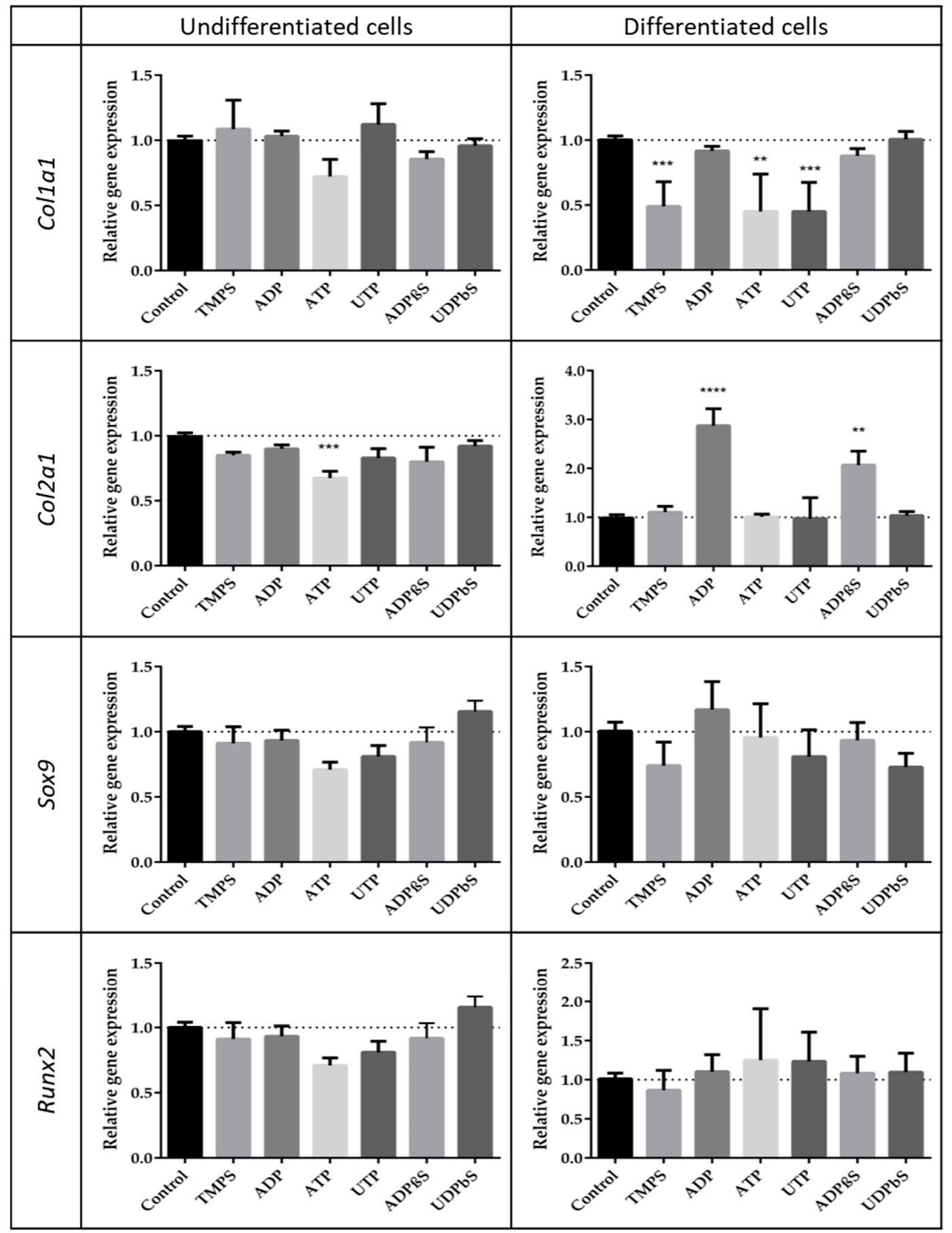

Figure 4. Expression patterns of chosen genes characteristic for the differentiation process in the presence of extracellular nucleotides or their phosphorothioate analogs. Col1a1, Col2a1, Sox9, and Runx2 mRNA levels were measured by RT-qPCR in ATDC5 cells grown for $48 \mathrm{~h}$ in standard growth medium or in differentiation medium. Each value was normalized to Gapdh the same sample. Data represent the means \pm SEM from at least six independent experiments. $p<0.01\left({ }^{* *}\right)$ and $p<0.001\left({ }^{* * *}\right)$ for gene expression significantly different from untreated control cells. 


\section{Discussion}

The migration ability of chondrocytes is considered essential for the repair of cartilage since, in order to cure a defect, cells that fill the damaged tissue should migrate into such a space $[2,7,26]$. If left untreated after injury, cartilage degenerates and leads to chronic osteoarthritis (OA) [27]. Unfortunately, pathological changes that take place in OA include decreased cell migration that in turn can cause additional undesirable aggregation of chondrocytes and changes in matrix components [28]. The development of new agents targeting the migratory potential of chondrocytes is, therefore, a constant need for the development of new therapeutic strategies leading to the recovery of the original properties of cartilage. Chondrocyte migration enhancement therapy was also shown to positively affect tissue-engineered cartilage integration [29].

There is growing evidence to suggest that extracellular nucleotides play a significant role in the regulation of cartilage physiology [30]. Chondrocytes, for example, employ purinergic signaling as part of the mechanotransduction cascade, which promotes chemical signaling inside the cell. Increased expression of the P2Y2 receptor was indicated to be responsible for the elevated extracellular signal-regulated kinase (ERK1/2) phosphorylation in response to oscillatory fluid flow, which in turn regulates a variety of chondrocyte activities, including migration, proliferation, and differentiation [31].

We and others have shown previously that P2Y receptors are involved in nucleotide-induced migration of many cell types $[8,9,32,33]$. In this research, we showed that the supplementation of chondrocytes with extracellular nucleotides has a profound effect also on migration. In the resting state, the intracellular ATP concentrations are very high, ranging from 1 and $5 \mathrm{mM}$ whereas it is much lower in the extracellular space, ranging in the nanomolar concentration (10-100 nM) [34]. However, the synovial fluid from normal and OA joints contains around $100 \mu \mathrm{M}$ ATP [35]. Although it is difficult to measure the concentration of extracellular nucleotides within the extracellular space, extracellular UTP levels were demonstrated to account for $10-30 \%$ of the ATP levels in both resting and mechanically stimulated cultured cells [36]. Following mechanical stress, e.g., stretch and shear stress, in hypoxic conditions and during infection, local extracellular concentrations can be expected to ensure both P2Y receptors. The articular cartilage is subject and responsive to mechanical stimuli, and mechanical force on the extracellular matrix of the cartilage is transferred to the chondrocytes [37]. The migratory behavior was tested by a scratch assay, which was able to mimic a potential in vitro cartilage repair. Our studies demonstrate that migration of differentiated chondrocytes can be positively controlled by ADP, UMPS, UTP $\gamma$ S, UDP $\beta S$, and ADP $\beta S$; however, the most spectacular increase was observed for ADP $\beta S$, UDP $\beta S$, and ADP. Interestingly, in undifferentiated ATDC 5 cells, we did not detect the promigratory activity of ADP $\beta S, \mathrm{UDP} \beta \mathrm{S}$, and ADP, implying that undifferentiated cells are less sensitive to their presence in the extracellular environment. In contrast, undifferentiated cells were positively triggered mostly by unmodified uridine nucleotides, suggesting the possibility that different signaling mechanisms may occur within these two cell populations. We hypothesize that the different responses between differentiated and undifferentiated ATDC5 cells may largely be due to different patterns of P2Y receptor expression.

Earlier studies have reported the expression of P2Y1, P2Y2, P2Y4, and P2Y6 receptors on mature articular chondrocytes $[11,38-40]$. However, the present study provides the first evidence revealing the expression of additional P2Y12, P2Y13, and P2Y14 receptor subtypes in chondrocytes, as well as confirming the expression of P2Y1, P2Y2, P2Y4, and P2Y6. We also showed that the differentiation process highly upregulated the expression of $P 2 y 1, P 2 y 2$, and P2y13 genes in ATDC5 cells. However, in contrast to P2y2, ADP-selective P2y1 and P2y13 appeared to be the two most abundant transcripts among all $P 2 y$ studied. The expression of $P 2 y 2$ was formerly demonstrated to be significantly increased in differentiated ATDC5 cells relative to undifferentiated cells [31]. On the other hand, most purinergic receptors were detected throughout all the zones of articular cartilage, except for P2Y2 being more limited only to superficial zone cells [39].

Taking into consideration the fact that ADP and its stable analog ADP $\beta S$ appeared to strongly modulate the migration of differentiated chondrocytes, one can presume that ADP-preferring P2Y 
receptors, namely P2Y1, P2Y12, or P2Y13 [10], might be involved in this process. Indeed, the changes in the activities of ADP and ADP $\beta S$ are in accordance with the high abundance of $P 2 y 1$ and $P 2 y 13$ mRNAs in differentiated cells, implying that upregulated expression of those two GPCRs may partly be responsible for the control of cellular migration. Besides, the difference in P2y1 and P2y13 expression between differentiated and undifferentiated ATDC 5 cells suggests the possibility that their ligands may be involved in the process of differentiation. Therefore, the next purpose of this study was to elucidate the influence of extracellular nucleotides on the differential/dedifferentiation characteristics of ATCD 5 cells by investigating chondrogenic (Col2a1, Sox9), hypertrophic (Run $x$ 2), and fibrocartilaginous (Col1a1) mRNA expression. Differentiated ATDC5 cells specifically expressed the chondrogenic Col2a1 transcript under the influence of ADP and ADP $\beta S$ whereas undifferentiated cultures did not. ADP and ADP $\beta S$ did not modulate the expression of the other genes under study. These data suggested that the highly elevated P2Y1 and P2Y13 receptors might be involved not only in the control of migration but also differentiation. This finding is consistent with the previous reports about mesenchymal stem cells (MSCs). It was shown that adipogenesis of MSCs is mediated through P2Y1 [41] whereas ADP $\beta S$ stimulates MSCs' differentiation into osteoblasts through P2Y13 [42].

The capability of ADP to enhance the migration and expression of the chondrogenic COL2A1 marker is relevant at the physiological level. The introduction of ADP or ADP $\beta S$ into the extracellular space can potentially substantially improve the repair of cartilage. This hypothesis is consistent with a demonstrated role of platelet-derived ADP, but not ATP, as the key mediator for platelet-promoted chondrocyte proliferation and cartilage repair in osteoarthritis. Chondrocytes co-cultured with platelets showed a P2Y1-dependent increase in bone morphogenetic protein 7 synthesis, and transplantation of platelet-treated chondrocytes showed better cartilage repair in the OA model [43].

It should be noticed, however, that not all nucleotides can be considered as beneficial stimulators of chondrocyte physiology. Hereby, the ATP exposure of differentiated ATCD5 promoted a significant decrease in migration. ATP was previously shown to induce cell cycle arrest and suppress the proliferative and migration capacity of MSCs [44]. To date, multiple contradictory interpretations of the effects of ATP on chondrocytes have been reported. Potentially deleterious properties of ATP were described in the context of loss of the cartilage extracellular matrix. Bovine nasal cartilage resorption was promoted in the presence of ATP whereas ADP was inactive [45,46]. Extracellular ATP has, in contrast, a chondroprotective effect on bovine articular cartilage [46]. The exemplary opposite results show that the final effect exerted by extracellular ATP and other nucleotides is complicated due to a number of factors, including cell-specific expression of the receptor subtypes on the one hand and, on the other hand, ecto-nucleotidases and other enzymes responsible for nucleotide breakdown. These enzymes include members of ecto-NTPDases (ecto-nucleoside triphosphate diphosphohydrolases), ecto-NPPs (ecto-nucleotide pyrophosphatase/phosphodiesterase), ecto-alkaline phosphatases, and ecto-5' -nucleotidases [47]. The nucleotide kinases also participate in the regulation of the extracellular nucleotide concentration by transferring the phosphate moiety between nucleotides. Although little is known about linking nucleotides and ecto-nucleotidases with chondrogenic migration and differentiation, specific expression of ecto-nucleotidases members is responsible for regulating the extracellular concentrations of ATP, adenosine, inorganic phosphate, and pyrophosphate [48]. It should be assumed that the observations made during our research are not only the effect of nucleotide activity as P2Y receptor ligands but also enzymatical hydrolysis by ecto-nucleotidases that might be differentiation state-dependent expressed. Purinergic receptors and ecto-enzymes probably generate an orchestrated cellular signaling cascade essential for the development and maintenance of chondrocytes.

In summary, the results of this research demonstrate that the presence of extracellular nucleotides, especially ADP, ADP $\beta S$, and UDP $\beta$ S, induces migration of differentiated ATDC5 cells. Additionally, ADP and ADP $\beta S$ specifically induced expression of the chondrogenic Col2a1 marker. This study also identified P2Y1 and P2Y13 receptors as possible regulators of the ADP- and ADP $\beta S$-stimulated chondrocyte migration and differentiation. We also intend to replicate the results on primary human chondrocytes to accurately and undoubtedly disclose the mechanisms and potential therapeutic 
value of extracellular nucleotides for cartilage repair. This novel finding both challenges our basic understanding of chondrocyte physiology and provides an opportunity for cartilage repair in the future. Our research is intended to supplement chondrocytes with exogenous nucleotides. A possible approach would be an incorporation of the most active compounds into scaffolds to stimulate cartilage regeneration. Since cartilage tissue engineering aims to obtain a structure mimicking native cartilage tissue through the combination of relevant cells, three-dimensional scaffolds, and extraneous signals, we think that incorporation of nucleotides into scaffolds could be used to successfully induce cartilage regeneration. The incorporation of different growth factors into various scaffolds has already been proven to stimulate chondrogenesis both in vivo and in vitro [49].

\section{Materials and Methods}

\subsection{Tested Compounds}

ADP, ATP, UDP, and UTP were purchased from Sigma-Aldrich (Merck KGaA, Darmstadt, Germany). Phosphorothioate analogs of nucleotides (TMPS, AMPS, UMPS, UDP $\beta S$, UTP $\gamma S$, ADP $\beta S$, and $\mathrm{ATP} \gamma \mathrm{S}$ ) were obtained from BioLog (Bremen, Germany).

\subsection{ATDC5 Cell Culture}

The chondrogenic mouse cell line ATDC5 was purchased from the Health Protection Agency (supplied by Sigma Aldrich, Saint Louis, MO, USA). Growth medium consisted of a mixture of Dulbecco's modified Eagle medium/Nutrient Mixture F12 (DMEM/F12 1:1) supplemented with 2 mM glutamine (Thermo Fisher Scientific, Waltham, MA, USA), 5\% fetal bovine serum (FBS, Thermo Fisher Scientific), and antibiotics (100 U/mL penicillin (Polfa Tarchomin, Warsaw, Poland), $100 \mathrm{mg} / \mathrm{mL}$ neomycin (Galfarm, Cracow, Poland), and $2.5 \mu \mathrm{g} / \mathrm{mL}$ amphotericin B (Thermo Fisher Scientific)). The culture was carried out at a temperature of $37^{\circ} \mathrm{C}$ in a humidified atmosphere with $5 \% \mathrm{CO}_{2}$.

\subsection{Culture Media and Cell Differentiation}

Two additional options (starving and differentiation medium) were used during experiments. Starving medium was composed of DMEM/F12 (1:1), 2 mM glutamine, and antibiotics. Differentiation medium was supplemented with Insulin-Transferrin-Sodium Selenite (ITS 100x, final compounds concentration in medium: $10 \mu \mathrm{g} / \mathrm{mL}$ insulin, $5.5 \mu \mathrm{g} / \mathrm{mL}$ transferrin, $67 \mathrm{ng} / \mathrm{mL}$ sodium selenite, Thermo Fisher Scientific), L-ascorbic acid (50 $\mu \mathrm{g} / \mathrm{mL}$, Sigma Aldrich), dexamethasone (100 nM, Sigma Aldrich), and Transforming Growth Factor - $\beta 2$ ( $10 \mathrm{ng} / \mathrm{mL}$, TGF- $\beta 2$, Sigma Aldrich). Differentiated chondrocytes were obtained by a 14-day incubation in differentiation medium in 6-well plates (for RNA isolation) or 24-well plates (for migration research).

\subsection{RNA Isolation and Reverse Transcription Quantitative Polymerase Chain Reaction}

Extraction of the total RNA from ATDC5 cells was performed with a Universal RNA Purification kit (EurX, Gdańsk, Poland) according to the manufacturer's recommendations. Subsequently, RNA was purified with DNase I (EurX) and then reverse-transcribed to cDNA with an NG dART RT kit (EurX). Primers for real-time PCR (Table 1) were designed with the NCBI's Primer-BLAST software (National Center for Biotechnology Information; Bethesda, MD, USA) based on proteins' sequences collected from the GenBank database and purchased from Genomed (Warsaw, Poland). Real-time RT-PCR was conducted using SG qPCR Master Mix (EurX) with a CFX96 ${ }^{\mathrm{TM}}$ detection system (C1000 Touch, Bio-Rad, CA, USA). Real-time products were electrophoretically separated in 3\% agarose gel in Tris/acetate/EDTA buffer enriched with nucleic acid stain (Midori Green Advance DNA stain, NIPPON Genetics, Japan). The expression of all genes was normalized to the expression of a Gapgh housekeeping gene. Relative gene expressions were calculated with the following formula:

$$
\text { Relative gene expression }(1)=2^{-\Delta \mathrm{Ct}}
$$




$$
\Delta \mathrm{Ct}=[\mathrm{Ct}(\text { target genes })-\mathrm{Ct}(\text { Gapdh })]
$$

Increases of gene expression (in comparison to the control) were calculated with Livak's method [24]:

$$
\text { Increase of gene expression }=2^{-\Delta \Delta C t}
$$

$$
\Delta \Delta \mathrm{Ct}=[\Delta \mathrm{Ct}(\text { stimulated })-\Delta \mathrm{Ct}(\text { control })]
$$

Table 1. Sequence of primers used in RT-qPCR reaction.

\begin{tabular}{cccc}
\hline Gene & $\begin{array}{c}\text { NCBI Reference } \\
\text { Sequence }\end{array}$ & Forward Primer & Reverse Primer \\
\hline$P 2 y 1$ & NM_008772 & TTATGTCAGCGTGCTGGTGT & CGTGTCTCCATTCTGCTTGA \\
\hline$P 2 y 2$ & NM_008773 & GAGGACTTCAAGTACGTGCT & ACGGAGCTGTAAGCCACAAA \\
\hline$P 2 y 4$ & NM_020621 & GGGGACAAGTATCGAAACCA & CACCCTCATAAGCAGGGAAG \\
\hline$P 2 y 6$ & NM_183168 & TGCTGTGTCAGAGGGAGTTTT & TCAGCCTTTCCTATGCTCGG \\
\hline$P 2 y 12$ & NM_001357008 & CTGAAGACCACCAGGCCATT & GGAATCCGTGCAAAGTGGAA \\
\hline$P 2 y 13$ & NM_028808 & GCACCAGAAGAGAGGCACAT & TAGGGGAAGAGTCGTCGTGT \\
\hline$P 2 y 14$ & NM_001287124 & GGAACACCCTGATCACAAAG & TGACCTTCCGTCTGACTCTT \\
\hline Col1a1 & NM_007742 & ATGCCGCGACCTCAAGATG & TGAGGCACAGACGGCTGAGTA \\
\hline Col2a1 & NM_031163 & AGGGCAACAGCAGGTTCACATAC & TGTCCACACCAAATTCCTGTTCA \\
\hline Runx2 & NM_009820 & CACTGGCGGTGCAACAAGA & TTTCATAACAGCGGAGGCATTTC \\
\hline Sox9 & NM_011448 & TCCCCGCAACAGATCTCCTA & AGGTGGAGTAGAGCCCTGAG \\
\hline Gapdh & NM_008084 & TCTCTGCTCCTCCCTGTTCC & CAATCTCCACTTTGCCACTGC \\
\hline
\end{tabular}

\subsection{Cell Migration Studies}

Confluent ATDC5 cell monolayers were used for the wound scratch migration test. A straight-edge scratch was made in each well with the use of a sterile $200-\mu \mathrm{L}$ pipet tip. Wells were then rinsed with phosphate-buffered saline (PBS, Thermo Fisher Scientific), and starving or differentiation medium was added. Media were subsequently supplemented with tested compounds to a final concentration of $100 \mu \mathrm{M}$. Closure of the gap by cell migration was measured immediately (time 0 ) and $48 \mathrm{~h}$ after scratching with the Leica M205C microscope and Leica Application Suite software(Leica, Wetzlar, Germany). Cell migration was presented as a percentage of the control wound closure calculated as the formula:

$$
\text { Reduction of scratch }=\frac{\Delta \text { area of scratch in stimulated cells }}{\Delta \text { area of scratch in unstimulated cells }} \times 100 \%
$$

where " $\Delta$ area of scratch in stimulated cells" — difference between scratch area at beginning of migration and after 48 hours of incubation in cells supplemented with tested compounds; and " $\Delta$ area of scratch in unstimulated cells" - average difference between scratch area at beginning of migration and after 48 hours of incubation in control cells.

\subsection{Statistical Analysis}

Cell migration and level of gene expression were analyzed by one-way ANOVA with a Bonferroni test. Results represent a mean value with a standard error of the mean. Two-way ANOVA was used to calculate the significance difference between the gene expression in differentiated and undifferentiated cells. Probabilities errors less than 0.05 were accepted as significant for all analyses. Differences between groups were rated significant at a probability error $p<0.05(*), p<0.01\left({ }^{* *}\right), p<0.001\left({ }^{* *}\right)$, and $p<0.0001\left(^{* * * *}\right)$. All calculations were performed with GraphPAD Prism 6 (GraphPad Software, La Jolla, CA, USA). 
Author Contributions: Conceptualization, E.G.-D.; methodology, M.S.; investigation, M.S.; writing-original draft preparation, E.G.-D. and M.S.; visualization, M.S.; supervision, E.G.-D. All authors have read and agreed to the published version of the manuscript.

Funding: This research received no external funding.

Conflicts of Interest: The authors declare no conflict of interest.

\section{Abbreviations}

\begin{tabular}{|c|c|}
\hline $\mathrm{ACI}$ & Autologous chondrocyte implantation \\
\hline ADP & Adenosine 5'-O-diphosphate \\
\hline ADP $\beta S$ & Adenosine $5^{\prime}-\mathrm{O}-\beta$-thiodiphosphate \\
\hline AMPS & Adenosine 5'-O-thiomonophosphate \\
\hline ATP & Adenosine $5^{\prime}$-O-triphosphate \\
\hline $\operatorname{ATP} \gamma \mathrm{S}$ & Adenosine $5^{\prime}-\mathrm{O}-\gamma$-thiotriphosphate \\
\hline DMEM & Dulbecco's modified Eagle medium \\
\hline FBS & Fetal Bovine Serum \\
\hline ITS & Insulin-Transferrin-Sodium Selenite \\
\hline MSCs & Mesenchymal stem cells \\
\hline OA & Osteoarthritis \\
\hline PBS & Phosphate-buffered saline \\
\hline RT-qPCR & Reverse transcription quantitative polymerase chain reaction \\
\hline SEM & Standard error of the mean \\
\hline TGF- $\beta 2$ & Transforming Growth Factor $\beta 2$ \\
\hline TMPS & Thymidine $5^{\prime}$-O-thiomonophosphate \\
\hline UDP & Uridine $5^{\prime}$-O-diphosphate \\
\hline UDP $\beta S$ & Uridine $5^{\prime}$-O- $\beta$-thiodiphosphate \\
\hline UMPS & Uridine $5^{\prime}$-O-thiomonophosphate \\
\hline UTP & Uridine 5'-O-triphosphate \\
\hline UTP $\gamma \mathrm{S}$ & Uridine $5^{\prime}-\mathrm{O}-\gamma$-thiotriphosphate \\
\hline
\end{tabular}

\section{References}

1. Akkiraju, H.; Nohe, A. Role of chondrocytes in cartilage formation, progression of osteoarthritis and cartilage regeneration. J. Dev. Biol. 2015, 3, 177-192. [CrossRef]

2. Hopper, N.; Henson, F.; Brooks, R.; Ali, E.; Rushton, N.; Wardale, J. Peripheral blood derived mononuclear cells enhance osteoarthritic human chondrocyte migration. Arthritis Res. Ther. 2015, 17. [CrossRef] [PubMed]

3. Chang, C.; Lauffenburger, D.A.; Morales, T.I. Motile chondrocytes from newborn calf: Migration properties and synthesis of collagen II. Osteoarthr. Cartil. 2003, 11, 603-612. [CrossRef]

4. Maniwa, S.; Ochi, M.; Motomura, T.; Nishikori, T.; Chen, J.; Naora, H. Effects of hyaluronic acid and basic fibroblast growth factor on motility of chondrocytes and synovial cells in culture. Acta Orthop. Scand. 2001, 72, 299-303. [CrossRef] [PubMed]

5. Hamilton, D.W.; Riehle, M.O.; Rappuoli, R.; Monaghan, W.; Barbucci, R.; Curtis, A.S.G. The response of primary articular chondrocytes to micrometric surface topography and sulphated hyaluronic acid-based matrices. Cell Biol. Int. 2005, 29, 605-615. [CrossRef]

6. Kirilak, Y.; Pavlos, N.J.; Willers, C.R.; Han, R.; Feng, H.; Xu, J.; Asokananthan, N.; Stewart, G.A.; Henry, P.; Wood, D; et al. Fibrin sealant promotes migration and proliferation of human articular chondrocytes: Possible involvement of thrombin and protease-activated receptors. Int. J. Mol. Med. 2006, 17, 551-558. [CrossRef] [PubMed]

7. Ge, X.; Shi, R.; Ma, X. The secreted protein WNT5A regulates condylar chondrocyte proliferation, hypertrophy and migration. Arch. Oral Biol. 2017, 82, 171-179. [CrossRef] [PubMed]

8. Węgłowska, E.; Szustak, M.; Gendaszewska-Darmach, E. Proangiogenic properties of nucleoside 5'-O-phosphorothioate analogues under hyperglycaemic conditions. Curr. Top. Med. Chem. 2015, 15. [CrossRef] [PubMed] 
9. Gendaszewska-Darmach, E.; Szustak, M. Thymidine 5'-O-monophosphorothioate induces HeLa cell migration by activation of the P2Y6 receptor. Purinergic Signal. 2016, 12, 199-209. [CrossRef]

10. Jacobson, K.A.; Delicado, E.G.; Gachet, C.; Kennedy, C.; Kügelgen, I.; Li, B.; Miras-Portugal, M.T.; Novak, I.; Schöneberg, T.; Perez-Sen, R.; et al. Update of P2Y receptor pharmacology: IUPHAR Review 27. Br. J. Pharmacol. 2020, 177, 2413-2433. [CrossRef]

11. Guzmán-Aránguez, A.; Irazu, M.; Yayon, A.; Pintor, J. P2Y receptors activated by diadenosine polyphosphates reestablish Ca2+ transients in achondroplasic chondrocytes. Bone 2008, 42, 516-523. [CrossRef] [PubMed]

12. Caswell, A.M.; Russell, R.G.G. Identification of ecto-nucleoside triphosphate pyrophosphatase in human articular chondrocytes in monolayer culture. BBA Mol. Cell Res. 1985, 847, 40-47. [CrossRef]

13. Drzazga, A.; Sowinska, A.; Krzeminska, A.; Rytczak, P.; Koziolkiewicz, M.; Gendaszewska-Darmach, E. Lysophosphatidylcholine elicits intracellular calcium signaling in a GPR55-dependent manner. Biochem. Biophys. Res. Commun. 2017, 489. [CrossRef] [PubMed]

14. Haanes, K.A.; Edvinsson, L. Expression and characterization of purinergic receptors in rat middle meningeal artery-potential role in migraine. PLOS ONE 2014, 9. [CrossRef] [PubMed]

15. Quintas, C.; Vale, N.; Gonçalves, J.; Queiroz, G. Microglia P2Y13 receptors prevent astrocyte proliferation mediated by P2Y1 receptors. Front. Pharmacol. 2018, 9. [CrossRef] [PubMed]

16. Davies, R.L.; Kuiper, N.J. Regenerative Medicine: A Review of the Evolution of Autologous Chondrocyte Implantation (ACI) Therapy. Bioengineering 2019, 6, 22. [CrossRef]

17. Liu, C.F.; Samsa, W.E.; Zhou, G.; Lefebvre, V. Transcriptional control of chondrocyte specification and differentiation. Semin. Cell Dev. Biol. 2017, 62, 34-49. [CrossRef]

18. Ushijima, T.; Okazaki, K.; Tsushima, H.; Iwamoto, Y. CCAAT/enhancer-binding protein $\beta$ regulates the repression of type II collagen expression during the differentiation from proliferative to hypertrophic chondrocytes. J. Biol. Chem. 2014, 289, 2852-2863. [CrossRef]

19. Caron, M.M.J.; Emans, P.J.; Coolsen, M.M.E.; Voss, L.; Surtel, D.A.M.; Cremers, A.; van Rhijn, L.W.; Welting, T.J.M. Redifferentiation of dedifferentiated human articular chondrocytes: Comparison of 2D and 3D cultures. Osteoarthr. Cartil. 2012, 20, 1170-1178. [CrossRef]

20. Challa, T.D.; Rais, Y.; Ornan, E.M. Effect of adiponectin on ATDC5 proliferation, differentiation and signaling pathways. Mol. Cell. Endocrinol. 2010, 323, 282-291. [CrossRef]

21. Ustun, S.; Tombuloglu, A.; Kilinc, M.; Guler, M.O.; Tekinay, A.B. Growth and differentiation of prechondrogenic cells on bioactive self-assembled peptide nanofibers. Biomacromolecules 2013, 14, 17-26. [CrossRef] [PubMed]

22. Yao, Y.; Zhai, Z.; Wang, Y. Evaluation of insulin medium or chondrogenic medium on proliferation and chondrogenesis of ATDC5 cells. BioMed Res. Int. 2014, 2014. [CrossRef] [PubMed]

23. Barlic, A.; Radosavljevic, D.; Drobnic, M.; Kregar-Velikonja, N. Advancing in the quality of the cells assigned for autologous chondrocyte implantation (ACI) method. In IFMBE Proceedings; Springer: Berlin/Heidelberg, Germany, 2007; Volume 16, pp. 249-252.

24. Livak, K.J.; Schmittgen, T.D. Analysis of relative gene expression data using real-time quantitative PCR and the 2- $\Delta \Delta \mathrm{CT}$ method. Methods 2001, 25, 402-408. [CrossRef] [PubMed]

25. Dreisig, K.; Kornum, B.R. A critical look at the function of the P2Y11 receptor. Purinergic Signal. 2016, 12, 427-437. [CrossRef]

26. Morales, T.I. Chondrocyte moves: Clever strategies? Osteoarthr. Cartil. 2007, 15, 861-871. [CrossRef]

27. Jiang, Y.; Tuan, R.S. Origin and function of cartilage stem/progenitor cells in osteoarthritis. Nat. Rev. Rheumatol. 2015, 11, 206-212. [CrossRef]

28. Schubert, T.; Anders, S.; Neumann, E.; Schölmerich, J.; Hofstädter, F.; Grifka, J.; Müller-Ladner, U.; Libera, J.; Schedel, J. Long-term effects of chondrospheres on cartilage lesions in an autologous chondrocyte implantation model as investigated in the SCID mouse model. Int. J. Mol. Med. 2009, 23, 455-460. [CrossRef]

29. Lu, Y.; Xu, Y.; Yin, Z.; Yang, X.; Jiang, Y.; Gui, J. Chondrocyte migration affects tissue-engineered cartilage integration by activating the signal transduction pathways involving Src, PLC $\gamma 1$, and ERK1/2. Tissue Eng. Part A 2013, 19, 2506-2516. [CrossRef]

30. Matta, C.; Fodor, J.; Csernoch, L.; Zákány, R. Purinergic signalling-evoked intracellular Ca ${ }^{2+}$ concentration changes in the regulation of chondrogenesis and skeletal muscle formation. Cell Calcium 2016, 59, 108-116. [CrossRef] 
31. Xing, Y.; Gu, Y.; Gomes, R.R.; You, J. P2Y2 receptors and GRK2 are involved in oscillatory fluid flow induced ERK1/2 responses in chondrocytes. J. Orthop. Res. 2011, 29, 828-833. [CrossRef]

32. Kenichi, N.; Tatsumi, M.; Zhao, M. An essential and synergistic role of purinergic signaling in guided migration of corneal epithelial cells in physiological electric fields. Cell. Physiol. Biochem. 2019, 52, 198-211. [CrossRef]

33. Girard, M.; Dagenais Bellefeuille, S.; Eiselt, É.; Brouillette, R.; Placet, M.; Arguin, G.; Longpré, J.; Sarret, P.; Gendron, F. The $\mathrm{P}_{2} \mathrm{Y}_{6}$ receptor signals through $\mathrm{G} \alpha_{\mathrm{q}} / \mathrm{Ca}^{2+} / \mathrm{PKC} \alpha$ and $\mathrm{G} \alpha_{13} / \mathrm{ROCK}$ pathways to drive the formation of membrane protrusions and dictate cell migration. J. Cell. Physiol. 2020. [CrossRef] [PubMed]

34. Corciulo, C.; Cronstein, B.N. Signaling of the purinergic system in the joint. Front. Pharmacol. $2020,10$. [CrossRef] [PubMed]

35. Ryan, L.M.; Rachow, J.W.; McCarty, D.J. Synovial fluid ATP: A potential substrate for the production of inorganic pyrophosphate. J. Rheumatol. 1991, 18, 716-720. [PubMed]

36. Lazarowski, E.R.; Harden, T.K. Quantitation of extracellular UTP using a sensitive enzymatic assay. Br. J. Pharmacol. 1999, 127, 1272-1278. [CrossRef]

37. Garcia, M.; Knight, M.M. Cyclic loading opens hemichannels to release ATP as part of a chondrocyte mechanotransduction pathway. J. Orthop. Res. 2010, 28, 510-515. [CrossRef]

38. Millward-Sadler, S.J.; Wright, M.O.; Flatman, P.W.; Salter, D.M. ATP in the mechanotransduction pathway of normal human chondrocytes. Biorheology 2004, 41, 567-575.

39. Knight, M.M.; McGlashan, S.R.; Garcia, M.; Jensen, C.G.; Poole, C.A. Articular chondrocytes express connexin 43 hemichannels and $\mathrm{P} 2$ receptors-A putative mechanoreceptor complex involving the primary cilium? J. Anat. 2009, 214, 275-283. [CrossRef]

40. Koolpe, M.; Pearson, D.; Benton, H.P. Expression of both P1 and P2 purine receptor genes by human articular chondrocytes and profile of ligand-mediated prostaglandin E2 release. Arthritis Rheum. 1999, 42, 258-267. [CrossRef]

41. Ciciarello, M.; Zini, R.; Rossi, L.; Salvestrini, V.; Ferrari, D.; Manfredini, R.; Lemoli, R.M. Extracellular purines promote the differentiation of human bone marrow-derived mesenchymal stem cells to the osteogenic and adipogenic lineages. Stem Cells Dev. 2013, 22, 1097-1111. [CrossRef]

42. Biver, G.; Wang, N.; Gartland, A.; Orriss, I.; Arnett, T.R.; Boeynaems, J.M.; Robaye, B. Role of the P2Y13 receptor in the differentiation of bone marrow stromal cells into osteoblasts and adipocytes. Stem Cells 2013, 31, 2747-2758. [CrossRef] [PubMed]

43. Zhou, Q.; Xu, C.; Cheng, X.; Liu, Y.; Yue, M.; Hu, M.; Luo, D.; Niu, Y.; Ouyang, H.; Ji, J.; et al. Platelets promote cartilage repair and chondrocyte proliferation via ADP in a rodent model of osteoarthritis. Platelets 2016, 27, 212-222. [CrossRef] [PubMed]

44. Semenova, S.; Shatrova, A.; Vassilieva, I.; Shamatova, M.; Pugovkina, N.; Negulyaev, Y. Adenosine-5'triphosphate suppresses proliferation and migration capacity of human endometrial stem cells. J. Cell. Mol. Med. 2020, 24, 4580-4588. [CrossRef] [PubMed]

45. Leong, W.S.; Russell, R.G.G.; Caswell, A.M. Stimulation of cartilage resorption by extracellular ATP acting at P2-purinoceptors. BBA Gen. Subj. 1994, 1201, 298-304. [CrossRef]

46. Brown, C.J.; Caswell, A.M.; Rahman, S.; Russell, R.G.G.; Buttle, D.J. Proteoglycan breakdown from bovine nasal cartilage is increased, and from articular cartilage is decreased, by extracellular ATP. Biochim. Biophys. Acta Mol. Basis Dis. 1997, 1362, 208-220. [CrossRef]

47. Zimmermann, H.; Zebisch, M.; Sträter, N. Cellular function and molecular structure of ecto-nucleotidases. Purinergic Signal. 2012, 8, 437-502. [CrossRef]

48. Graff, R.D.; Picher, M.; Lee, G.M. Extracellular nucleotides, cartilage stress, and calcium crystal formation. Curr. Opin. Rheumatol. 2003, 15, 315-320. [CrossRef]

49. Kazemnejad, S.; Khanmohammadi, M.; Baheiraei, N.; Arasteh, S. Current State of Cartilage Tissue Engineering using Nanofibrous Scaffolds and Stem Cells. Avicenna J. Med. Biotechnol. 2017, 9, 50-65.

(C) 2020 by the authors. Licensee MDPI, Basel, Switzerland. This article is an open access article distributed under the terms and conditions of the Creative Commons Attribution (CC BY) license (http://creativecommons.org/licenses/by/4.0/). 